\title{
Stability Analysis of Tailing Dam Based on Geo-Studio
}

\author{
Zhi-fei Song ${ }^{1, a}$, Teng Ma ${ }^{2, b}$ and Zeyin Zhao ${ }^{3, c}$ \\ 1, , , 3 No.5 Jin Yuan Zhuang Road, Shi Jing Shan District, Beijing, China \\ a song59672@163.com, b1084534544@qq.com, '1062658788@qq.com
}

Keywords: Tailings dam; Stability; Seepage line; Safety coefficient; Drainage.

Abstract. Based on the seepage conceptual model of present elevation and ultimate elevation, in the conditions of common water level and flood level, SEEP/W, the seepage analysis module of GEO-Studio was utilized to simulate the changing regularity of seepage field, and then the results will be substituted into the module of SLOPE/W to calculated for the minimum safety factor and sliding surface, from the stability calculation result, in the conditions of drainage facilities working normally, the slope stability of tailing dam can satisfy the requirements of the minimum safety coefficient. But in the ultimate elevation flood water level, the safety coefficient is not high enough. At the same time, the effect of rising water level on the seepage line position and the dam stability is analyzed. The result can be of certain reference and guidance importance to the safe operation of tailing reservoir.

\section{Introduction}

With the rapid development of mining production, The number of Tailings reservoir which are an important part of the production facility is continuously increasing. The height of tailings dam is raising with the increasing demand for mining. The safe operation of the Tailings reservoir is the most important work. Once there happens accident, which proves to be devastating, not only causing direct economic losses such as mine closure, etc., it will also lead to a lot of property damage and casualties and serious environmental pollution and other issues. Currently, there are some security risks about many domestic Tailings at different degrees. The key to the safe operation of the Tailings reservoir is that tailings dam body must be safe and secure. Therefore, in order to prevent the occurrence of tailings dam accidents, the stability assessment is absolutely necessary for the rise and late of tailings dam, and it's very significant.

The research of tailings dam seepage and stability analyzes has been a hot topic in the field of mine safety and difficulties. At present, some scholars have studied the role in terms of water, tailings dam seepage and dam stability analysis method.

\section{Engineering Survey.}

A tailings pond in northern China is surrounded by mountains, facing the empty hillside type of tailings, using the method of upstream processes. The initial dam is $16 \mathrm{~m}$ high and $74.4 \mathrm{~m}$ long permeable rock-fill dam, and the crest elevation is $228 \mathrm{~m}$. The upriver ratio of slope is $1: 1.7$, and the lower reaches is $1: 1.6$, a $2 \mathrm{~m}$ wide road will be seted at the elevation of $220 \mathrm{~m}$. the late stacking dam will be done with the method the pool filling to set the ancillary dam, dispersive management and Scattered pile up, the present elevation of accumulation dam is $285 \mathrm{~m}$, in order to fit the requirements of actual production, we will increase the capacity of the tailing pond later. Eventually it is raised to $300 \mathrm{~m}$ elevation, The dam is $88 \mathrm{~m}$ high. And the total capacity is $17.1 \mathrm{million}^{3}$ below Elevation of $300 \mathrm{~m}$, the service life of the tailings dam is about 16 years. Currently fill dam level has been raised to $285 \mathrm{~m}$, High of $73 \mathrm{~m}$. the total capacity is 10 million $\mathrm{m}^{3}$ below Elevation of $285 \mathrm{~m}$, according to Safety technical regulations for the tailing pond, The present situation of tailings are the third class library.

There are companies, orchards, farmland and reservoirs in the tailings downstream, etc. Once collapse accident happens, it will cause serious casualties, severe damage to soil pollution, water pollution, air pollution and so on. Therefore, the study of the tailings security and stability is of great significance. 


\section{The Research Methods.}

The Basic Theory of Stability Calculation.In China, the research on the stability of tailings have started lately, and it has not formed an analytical system about independent stability, while using the analytical method of stability on side slope of soil. Generally it's divided into three categories: limit equilibrium method, such as Sweden method, Bishop method, residual thrust method; numerical analysis methods, such as finite element method, finite difference method, boundary element method; probability analysis method, such as Monte Carlo method, a second order moment method ${ }^{[8-9]}$ (FOSM), FORM, AFORM etc. At present, the method of slope stability analysis based on limit equilibrium theory is the most widely used.

According to Concentrator Tailings Facilities Design Specification and Safety Technical Regulations for the Tailing pond (AQ2005-2006), the stability of the tailings dam is suitable for the use of the Swedish arc method. As it's shown in Fig.1.

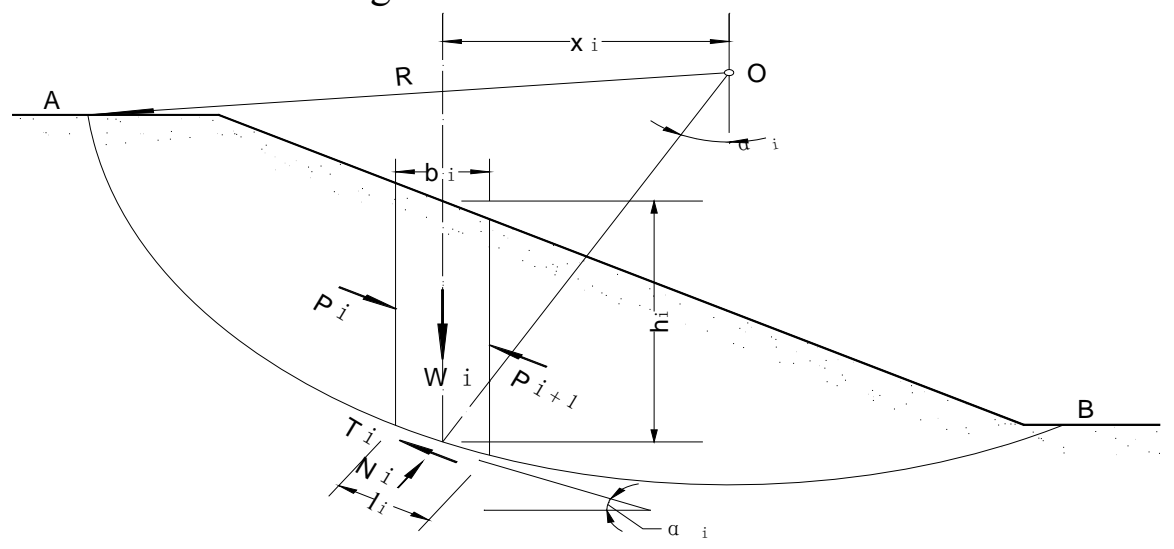

Fig. 1. the Swedish arc method

This method that the slider is divided into different slices and the shear strength of the fracture surface of soil followed the Mohr-Coulomb strength criterion to solve the safe factor without trap and block inter-atomic forces in consideration, is more simple.Although there are some shortcomings in the theory ,its application has 80 years of history, so in the project it is still widely used. And its calculation formula is followed:

$$
F_{s}=\frac{\sum\left(c_{i} l_{i}+W_{i} \cos \theta_{i} \operatorname{tg} \varphi_{i}\right)}{\sum W_{i} \sin \theta_{i}}
$$

Considering the dam's body with the seepage effect, many people often use alternative severe methods to calculate the project. That's named article middle density formula in the saturation line above part adopts natural bulk density, using the saturated unit weight while infiltrating the following. This method not only considers the effect of stable seepage flow on slope stability, but makes the calculation more convenient. In addition, its precision can better meet the needs of the project, but it should be noted that bulk density substitution method is only an empirical formula. When the slope stability is undering the action of seepage, bulk density can be calculated in substitution method, and it's concrete formula is as follows:

$$
F_{s}=\frac{\sum\left[c_{i} l_{i}+\left(\gamma h_{1 i}+\gamma^{\prime} h_{2 i}\right) b_{i} \cos \theta_{i} \tan \varphi_{i}\right]}{\sum\left(\gamma h_{1 i}+\gamma_{s a t} h_{2 i}\right) b_{i} \sin \theta_{i}}
$$

In the formula,

$c_{i}$ - the total stress shear strength index of the soil body of cohesion, the unit is $\mathrm{kPa}$;

$\varphi_{i}$ — total stress shear strength index of soil mass index internal friction angle, it's unit is degree;

$l_{i}$ _Soil weight sliding surface length slice, the unit is $\mathrm{kN}$;

$\theta_{i}$-Dip - slip block, it's unit is degree; 
$\gamma \cdot \gamma^{\prime} \cdot \gamma_{\text {sat }}$ - the soil bulk density, bulk density and saturated unit weight of soil, respectively, the unit is $\mathrm{kN} / \mathrm{cm}^{3}$;

$h_{1 i} h_{2 i}$ - The soil height of the block I on or below the saturation line of compartmentalization.

To make the Bishop method simple, the method takes the force between soil tripes in consideration, which is an important improvement on traditional Swedish methods. This method ignores the tangential force between the soil, which thinks that the force between the resultant is horizontal. The specific formula is in the following :

$$
\begin{gathered}
F_{s}=\frac{\sum \frac{1}{m_{\theta i}}\left(c_{i} l_{i} \cos \theta_{i}+W_{i} \tan \varphi_{i}\right)}{\sum W_{i} \sin \theta_{i}} \\
m_{\theta i}=\cos \theta_{i}+\frac{\sin \theta_{i} \tan \varphi_{i}}{F}
\end{gathered}
$$

The Simplified Bishop replaces the formula of severe method:

$$
F_{s}=\frac{\sum \frac{1}{m_{\theta i}}\left[c_{i} b_{i}+\left(\gamma h_{1 i}+\gamma^{\prime} h_{2 i}\right) b_{i} \tan \varphi_{i}\right]}{\sum\left(\gamma h_{1 i}+\gamma_{s a t} h_{2 i}\right) b_{i} \sin \theta_{i}}
$$

The parameters in the formula are the same as above.

Geo - Studio is a professional, more efficient and powerful simulation software of the environment for geotechnical engineering and geotechnical, which is widely used in the geotechnical engineering design and analysis. This paper adopts the SEEP/W module for the seepage field simulation, and then with the result joined SLOPE/W module to calculate the safety factor, and finally getting one of the most dangerous sliding surface in the coupling cases.

SLOPE/W takes the limit equilibrium method as the calculation principle to carry on the slope stability analysis. It is nested Ordinary method, Bishop method, Janbu method, Morgenstem Price (abbreviation M-P) method and so on. In the calculation, the definition of the problem is simple, and can be used to solve the minimum safety factor and the most dangerous sliding surface[10].

\section{Computational Models and Parameters.}

Profile of Model.The calculation model depends on the maximum section of the dam axis, as shown in Fig.1, Fig. 2.

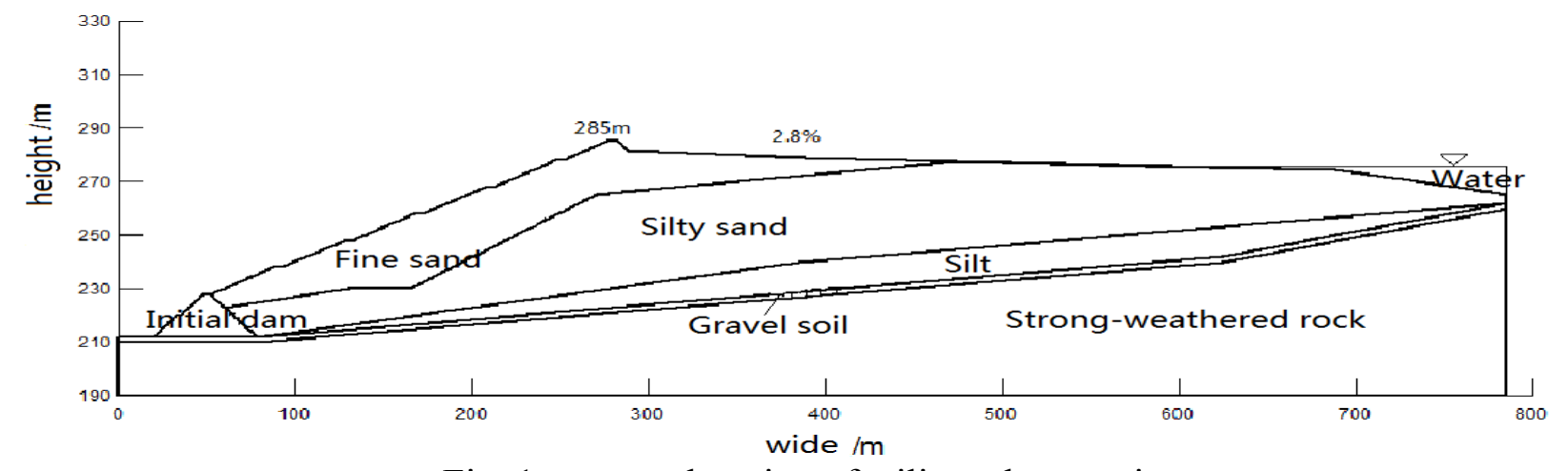

Fig. 1 current elevation of tailings dam section 


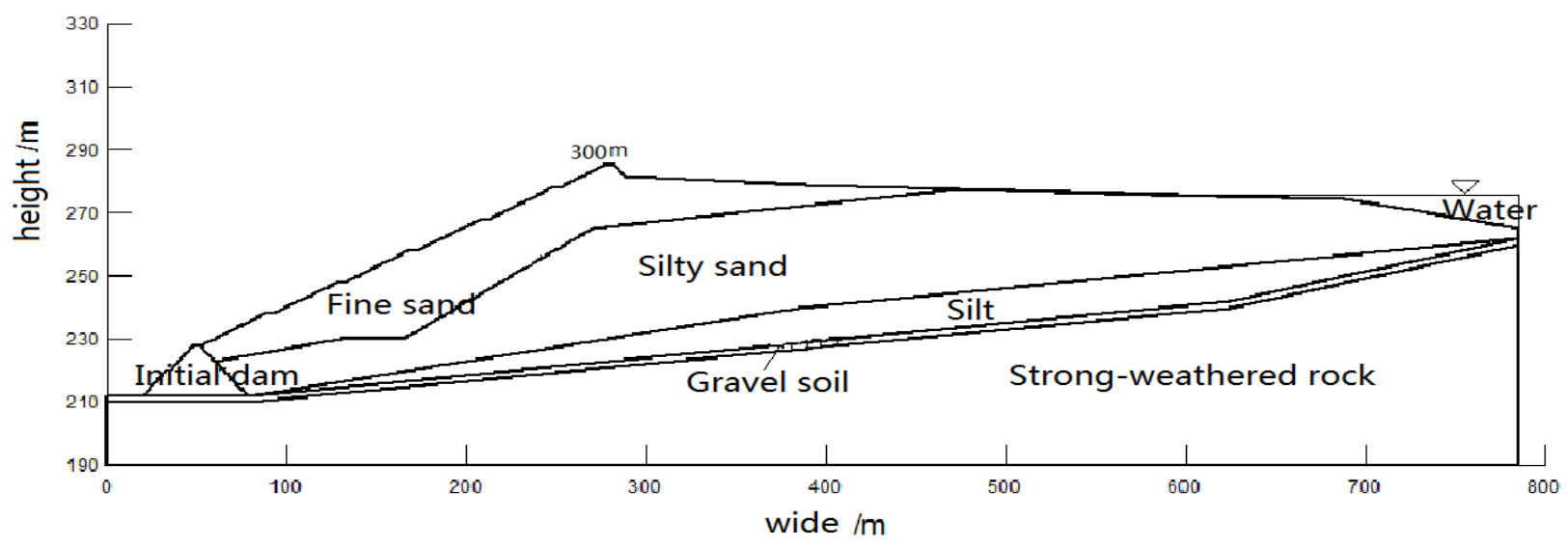

Fig. 2 the final height of the tailings dam section

Physical and Mechanical Parameters of Materials. According to Concentrator Tailings Facilities Design Specification, ZBJ1-90 [11], and the physical and mechanical parameters of the soil layer, the calculated parameters are listed in Table 1.

Table 1. the main dam body material mechanics calculation parameter table

\begin{tabular}{lcccccccc}
\hline Material & $\begin{array}{c}\text { Permeability coefficient } \\
\mathrm{K}(\mathrm{cm} / \mathrm{s})\end{array}$ & $\begin{array}{c}\text { Natural unit } \\
\text { weight } \\
\mathrm{r}\left(\mathrm{kN} / \mathrm{m}^{3}\right)\end{array}$ & $\begin{array}{c}\text { Saturated bulk } \\
\text { density } \\
\mathrm{r}_{\mathrm{m}}\left(\mathrm{kN} / \mathrm{m}^{3}\right)\end{array}$ & $\begin{array}{c}\mathrm{n} \\
\text { Porosity }\end{array}$ & $(\mathrm{Kpa})$ & $\begin{array}{c}\varphi \\
\left({ }^{\circ}\right)\end{array}$ & $\begin{array}{c}(\mathrm{KPa}) \\
\left({ }^{\circ}\right)\end{array}$ \\
\hline Initial dam & $5.03 \mathrm{e}-4$ & 18.0 & 20.0 & 0.52 & 20 & 38 & 20 & 38.0 \\
Fine sand & $1.3 \mathrm{e}-3$ & 16.3 & 19.6 & 0.53 & 0 & 31.6 & 0 & 30.6 \\
Tail powder & $3.75 \mathrm{e}-4$ & 15.9 & 19.5 & 0.47 & 0 & 31 & 0 & 30.0 \\
Silt soil & $1.25 \mathrm{e}-4$ & 15.6 & 19.4 & 0.56 & 8.0 & 24.0 & 8.0 & 22.0 \\
Gravel soil & $7.03 \mathrm{e}-4$ & 17.0 & 20.0 & 0.51 & 15.0 & 28.0 & 0.0 & 28.0 \\
Strong weathered & $1.0 \mathrm{e}-4$ & 18.0 & 20.0 & 0.40 & 35.0 & 35.0 & 15.0 & 35.0 \\
rock & & & & & & & & \\
\hline
\end{tabular}

Calculating Conditions. According to the present situation of tailings dam and the physical and mechanical parameters of tailings dam, the $285 \mathrm{~m}$ and ultimate $300 \mathrm{~m}$ elevation of tailings dam are analyzed. At the same time, the elevation is also considered the following two cases:

(1) normal operating conditions of the dam

(2) the highest flood stage

The flood level is obtained by the local hydrological meteorological data and the water level is calculated.

\section{Stability analysis of dam.}

In this calculation, first, the current status of the dam is checked, and then the final height of the dam is predicted, and the anti sliding stability of the dam is calculated. Taking into account the current use of drainage wells, drainage, drainage, such as blind ditch seepage.

The stability calculation takes the maximum section of vertical dam axis, then makes the calculation to both get the two kinds of elevation of the dam in the normal water level and flood position of the tailings dam, also get the most unfavorable sliding surface and the minimum safety factor. The calculation results are shown in Table 2 and Fig.3, Fig.4, Fig.5, Fig.6. 
Table 2. Summary of calculation results

\begin{tabular}{|c|c|c|c|c|c|c|c|c|}
\hline \multirow[b]{2}{*}{ Elevation } & \multirow[b]{2}{*}{$\begin{array}{l}\text { Operating } \\
\text { condition }\end{array}$} & \multirow[b]{2}{*}{$\begin{array}{c}\text { codeslstan } \\
\text { dards }\end{array}$} & \multicolumn{5}{|c|}{ Calculation results ( stability factor ) } & \multirow[b]{2}{*}{ Evaluation } \\
\hline & & & $\begin{array}{c}\text { M-P } \\
\text { method }\end{array}$ & $\begin{array}{l}\text { Bishop } \\
\text { method }\end{array}$ & $\begin{array}{l}\text { JanBu } \\
\text { method }\end{array}$ & $\begin{array}{l}\text { slices } \\
\text { method }\end{array}$ & $\begin{array}{c}\text { average } \\
\text { value }\end{array}$ & \\
\hline \multirow[b]{2}{*}{$\begin{array}{l}\text { At present } \\
285 \mathrm{~m}\end{array}$} & Normal & 1.20 & 1.60 & 1.65 & 1.49 & 1.46 & 1.55 & \multirow[b]{2}{*}{ Meet } \\
\hline & $\begin{array}{c}\text { Highest } \\
\text { water level }\end{array}$ & 1.10 & 1.42 & 1.46 & 1.39 & 1.35 & 1.40 & \\
\hline \multirow{2}{*}{$\begin{array}{l}\text { Final height } \\
\quad 300 \mathrm{~m}\end{array}$} & Normal & 1.20 & 1.44 & 1.50 & 1.42 & 1.39 & 1.44 & \multirow[b]{2}{*}{ Meet } \\
\hline & $\begin{array}{c}\text { Highest } \\
\text { water level }\end{array}$ & 1.10 & 1.27 & 1.31 & 1.25 & 1.22 & 1.26 & \\
\hline
\end{tabular}

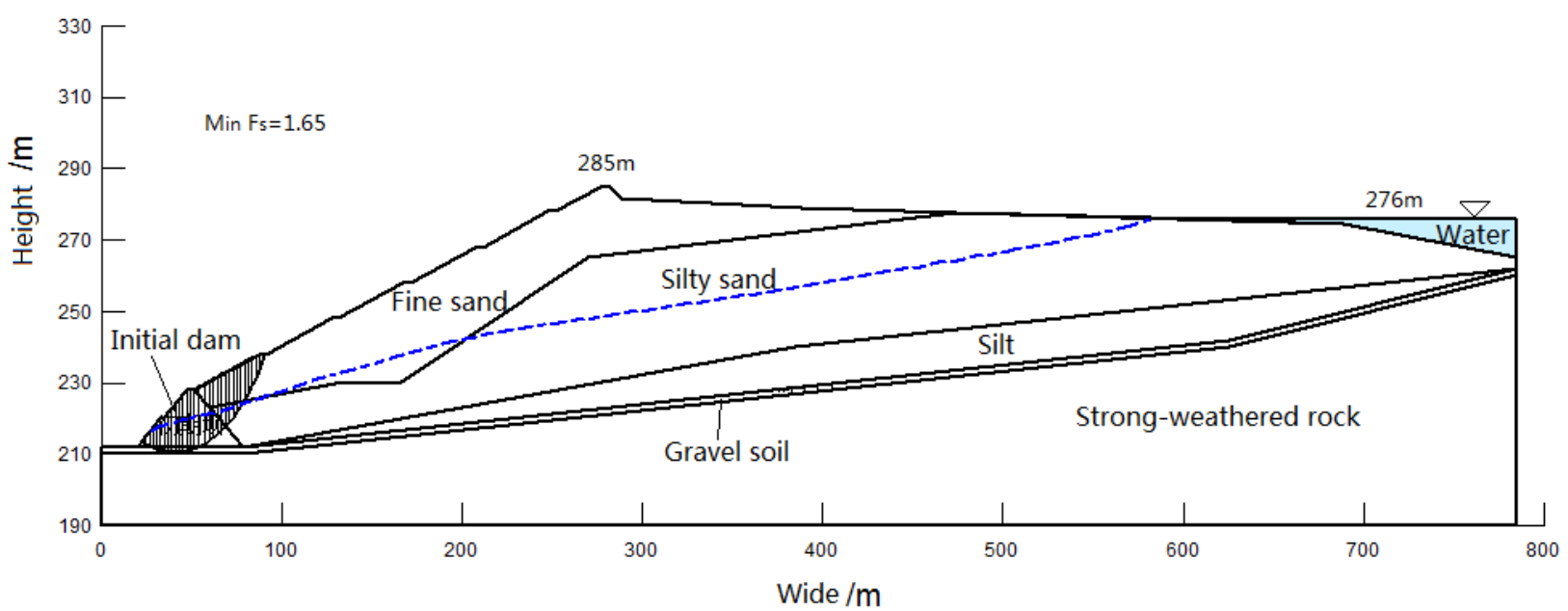

Fig. 3 the dam body stability analysis model (Bishop method) at present.

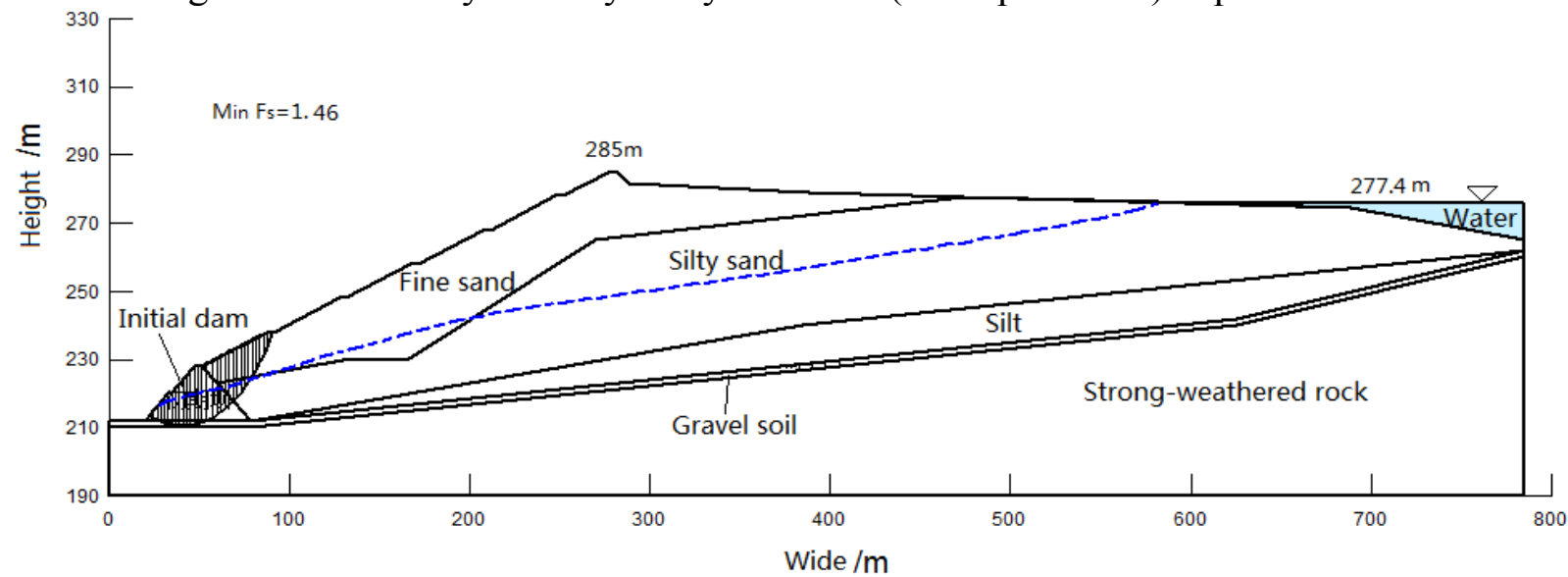

Fig. 4 the dam body stability analysis model (Bishop method) at present.

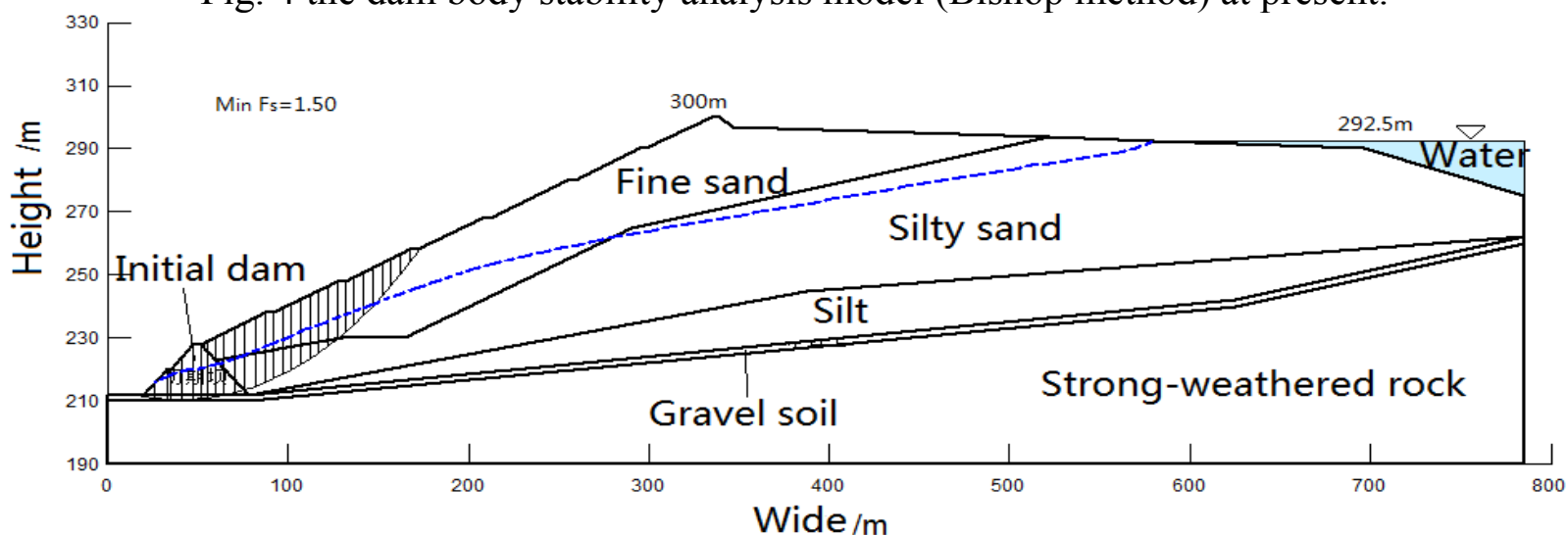

Fig. 5 the stability analysis model of the dam body at the end of the high normal water level (Bishop) 


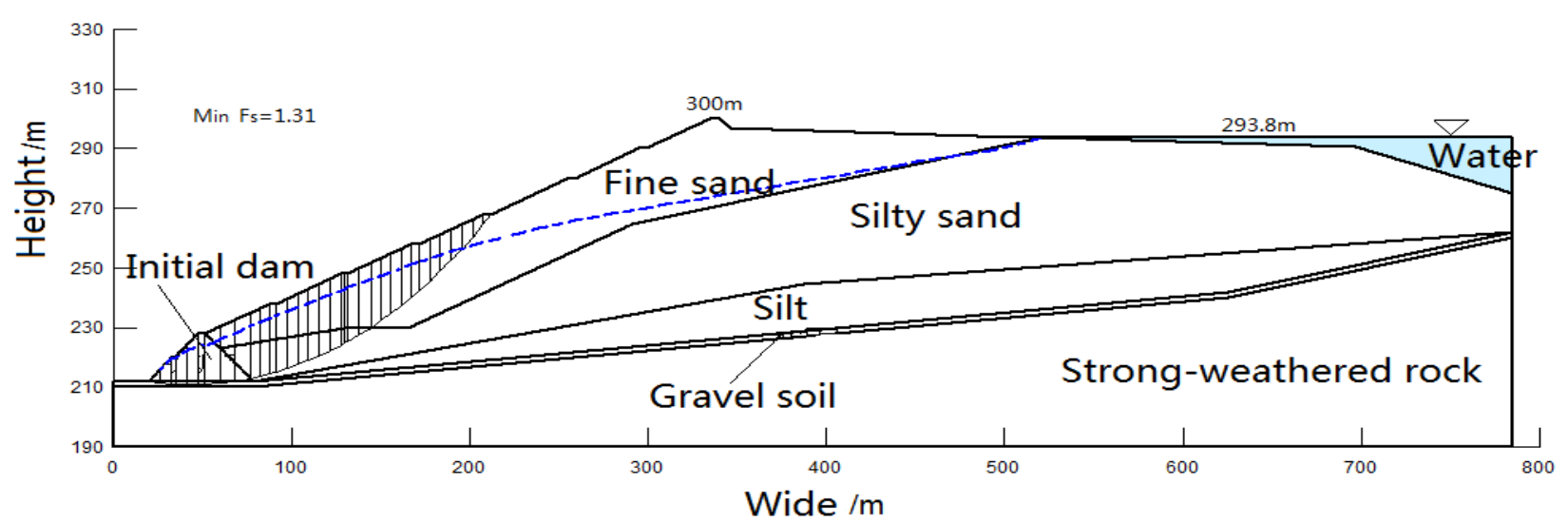

Fig. 6 the stability analysis model of the dam body at the end of the high flood stage (Bishop)

The stability calculation shows that the stability safety factor of two kinds of tailings dam is greater than the standard value, and can be seen in the normal operation and flood operation condition. It can be seen from the graph that the increase of water level in reservoir can improve the upstream water head, shorten the seepage path, also raise the height of the line.

In addition, there is little change in the same elevation of the dam under the two working conditions, but the increase of the water pressure of the sliding arc can increase the strength of the material, and the possibility of the failure of the material is increased.

\section{Summary}

(1) The elevation of water level in the reservoir shortens the seepage path, improves the upstream water head, and has a direct influence on the seepage field boundary. Therefore, from the point of view of the long-term safe operation of the tailing dam, we must strictly control the water level in the reservoir, and meet the safety of Long Beach, safe and high and stable requirements.

(2) At present, the slope of the tailings is $2.8 \%$, which is steeper, and with the increase of the water level in reservoir, it is likely that the line is away from the tailings dam slope. Therefore, it is suggested that the accumulation of dam is enhanced in the late stage, and the seepage destroy of the dam is prevented. By Duan Yuping's et al. Research, horizontal and vertical combined drainage can play a great effect of drainage [13].

(3) From the results of the stability calculation, the stability of the tailings dam slope is satisfied with the minimum safety factor of the standard in the case of the normal operation of the drainage facilities. But final high flood level dam safety coefficient of surplus is not great, so with the dam constantly heightening, dealing with tailings dam is reinforced, especially during the rainy season should reinforced platoon infiltration facilities of effective operation, in order to eliminate the security hidden danger and to maintain the stability of the dam safety. For the failure of the drainage facilities, we need to do a special study.

(4) During the operation of the tailing reservoir, it is suggested to strengthen the monitoring, and analyze the mechanical test and calculation results of different periods to ensure the safe operation of the tailing reservoir.

\section{Acknowledgements.}

This work was financially supported by the National Natural Science Foundation of China (41202214), Science and Technology Beijing Nova Plan (Z121106002512008). 


\section{References}

[1] Minxia Ning, Zhenwei Wang, Xinyu Yin. Research on the effect of water on stability of tailings[J],Express Information of Mining Industry 2006443 (5):43-44

[2] Huail Qin, Machi Ka. Study on the mechanism of the effect of water on the stability of tailings dam [J]. Metal Mine, 2008 (10): 116-117..

[3] Li Gen, Laigui Wang, Chen Fu, et al. Numerical simulation of the seepage stability of a tailing reservoir [J]. Metal Mine, 2008 (9): 123-125..

[4] Liang Li, Li Ming, Wang Wei, et al. Numerical analysis of stability of tailings reservoir [J]. Journal of Safety Science and Technology, 2007, 3 (5): 11-15.

[5] Dianqiang Chen, Laigui Wang, Li Gen. Stability analysis of tailings dam [J]. Journal of Liaoning Technical University(Natural Science), 2008, 27 (3): 359-361.

[6] Shaohua Hu, Wang Tao et al. Analysis of the numerical calculation and analysis of the seepage and stability of a tailing reservoir [J]. Sci-Tech Information Development \& Economy, 2010,20 (12):140-142

[7] AQ2005-200 Safety technical specification for tailing reservoir [S]

[8] Kunlong Yin, Haibo Miu, Fusan Guo et al. Numerical analysis of seepage field and stability of metal mine tailings dam [J]. Metal Mine 2010,405 (3): 134-137.

[9] Chixiang Ma, Huali Qin. Research on the stability of tailings dam based on the stability analysis of the stability of the tailings dam [J]. Industrial Safety and Environmental Protection, 2008,34 (9): $32-34$

[10]Cui Xuan, Hanmin Zhou, Xiaofei Liu. Calculation and analysis of the influence of the saturation line in the dam on the stability of the tailings dam. Mining Engineering (Suppl.), 2011,127-130.

[11] (ZBJ1-90) 2005, Code for design of tailings facilities in ore dressing plant (S)

[12] Li Liang,Xuesong Chu, Study on the effect of phreatic line depth on the evaluation of slope stability for tailing dam[J]. Journal of safety science and technology, 2011,7 (3): 98-103. (11): 20-23

[13] Wei Ping Duan, Xiubao Wei, Hu bin.Practice of seepage flow analysis and stability study of fine particles-constructed tailings dam. Metal mine, 2004, supplement 484-488. 